\title{
EXPANSÃO URBANA: REFLETINDO EM TORNO DA TIPOLOGIA DA CIDADE DE MAPUTO
}

\author{
Urban expansion: reflecting around the typology of Maputo city \\ Luiz Adriano Guevane \\ Universidade Pedagógica de Maputo - Faculdade de Cências da Terra e Ambiente, \\ Departamento de Geografia \\ luisguevane@gmail.com
}

Artigo recebido em 30/10/2019 e aceito para publicação em 01/05/2020

DOI: $10.12957 /$ tamoios.2020.46204

\begin{abstract}
Resumo
A partir de uma aproximação teórica respaldada em diversa bibliografia seguida de uma abordagem sistémica e histórica sobre o tema, o presente estudo procura perceber até que ponto a expansão da cidade de Maputo é do tipo anéis concêntricos, ou se esta tipologia foi reconfigurada criando uma outra à luz da intensificação do processo de urbanização no âmbito da transição urbana. Evidências empíricas mostram que a expansão urbana extensiva da capital da República de Moçambique, como parte da intensificação do processo global de urbanização, continua a manter o essencial da tipologia colonial, tanto nos seus aspectos assimétricos infraestruturais como socio-espaciais. Os contrastes entre o centro urbano e a periferia, sobretudo dentro desta, são produto de uma expansão urbana extensiva ativada por um mercado de terras informal. Daqui resulta a valorização de novos espaços à custa de habitações de padrão diferenciado no meio suburbano e periurbano. A referida expansão urbana extensiva, genericamente do tipo anéis concêntricos, evidencia, para fora do seu perímetro urbano, um continuum, ou seja, uma etapa crescentemente mais conformada com a urbanização dispersa.
\end{abstract}

Palavras-chave: expansão urbana; transição urbana; tipologias urbanas; centro urbano; anéis concêntricos.

\begin{abstract}
Based on a theoretical approach backed by a diverse bibliography followed by a systemic and historical approach on the subject, the present study seeks to understand the extent to which the expansion of Maputo city is of the concentric rings type, or whether this typology was reconfigured by creating another in the light of the intensification of the urbanization process within the urban transition. Empirical evidence shows that the extensive urban expansion of the capital of the Republic of Mozambique, as part of the intensification of the global process of urbanization, continues to maintain the essentials of the colonial typology, both in its asymmetric aspects Infrastructural as socio-spatial. The contrasts between the urban centre and the periphery, especially within it, are the product of extensive urban sprawl triggered by an informal land market. As a result, new spaces are being valued at the expense of suburban and periurban housing. This extensive urban expansion, generally of the concentric ring type, shows, outside its urban perimeter, a continuum, that is, a step increasingly conformed to dispersed urbanization.
\end{abstract}

Keywords: urban expansion; urban transition; urban typologies; urban centre; concentric rings. 


\section{Introdução}

Vários estudos empíricos realizados sobre as cidades constataram existir relações complexas entre os diversos elementos urbanos, confirmando-se, assim, um dos princípios fundamentais da teoria dos sistemas aplicado às cidades - a complexidade. Deste modo, "analisar as cidades enquanto um sistema se tornou possível e, de certa forma, cada vez mais simples de se realizar", à medida que "se identificavam os subsistemas da cidade e compreendiam suas interações" (Naciff, Kneib e Amaral, 2019: 14).

Essas relações complexas perfazem, no caso em apreço, a expansão urbana extensiva da cidade de Maputo (Longitude: $32^{\circ} 25^{\prime}$ a $32^{\circ} 40^{\prime}$ | Latitude: $25^{\circ} 50^{\prime}$ a $26^{\circ} 05^{\prime}$, Sul | Altitude: 0 a 60 metros), que continua a manter o essencial da tipologia urbana colonial, tanto nos seus aspectos assimétricos infraestruturais como socio-espaciais. Tais assimetrias não encontram exclusividade nas diferenças histórico-sociais e espaciais no sentido centro-periferia; revelam-se cada vez mais nitidamente ao nível da complexidade da morfologia urbana, sobretudo na periferia urbana (espaço suburbano e periurbano), por meio da mudança no padrão habitacional fruto de uma economia de mercado e dominada por um mercado de terras informal.

Teoricamente, o estudo recorre às abordagens tipológicas sobre a expansão urbana feitas tanto por España (1991, referido por Vale e Gerardi, 2006) como por Japiassú \& Lins (2014), buscando conformar a tipologia urbana da cidade de Maputo estudada por Araújo (1999). Tomando em conta, no geral, a complexidade da cidade e, em particular, a consideração fronteiriça ou delimitadora do espaço urbano, a intensificação do processo de expansão urbana sugere uma etapa cada vez mais conformada com a urbanização dispersa, que ocorre para fora do atual perímetro administrativamente considerado como cidade de Maputo mas umbilicalmente consistente com as dinâmicas socio-espaciais que perfazem a tipologia urbana da capital moçambicana. Neste sentido, três momentos fundamentais corporizam o estudo.

O primeiro momento é inerente aos vários aspectos da atual transição urbana no quadro da intensificação do processo global de urbanização. É analisada a expansão urbana na perspetiva da atual transição urbana, buscando referências nos contextos morfológicos de cidades africanas de génese colonial, nomeadamente as dos PALOP (Países Africanos de Língua Oficial Portuguesa), devido às similitudes histórico-urbanas que produziram espaços de precariedade e de várias formas de pobreza. As tipologias urbanas conformam-se com os desafios decorrentes da rápida urbanização dissociada do desenvolvimento económico.

O segundo momento é dedicado à contextualização, conceptualização de "expansão urbana" e identificação de tipologias urbanas, em busca de paralelismo com a realidade moçambicana, tendo como foco a contemporaneidade da tipologia da cidade de Maputo.

O terceiro momento aborda o processo de expansão extensiva da cidade de Maputo, a génese dos contextos morfológicos contrastantes e a tipologia em anéis concêntricos; um percurso histórico que enquadra os desafios decorrentes da rápida urbanização sem perder de vista os impactos dos ambientes político e económico na referida expansão.

\section{Intensificação do processo global de urbanização}

No processo de crescimento acelerado de cidades modernas, o seu núcleo tradicional passava por transformações e formavam-se, à sua volta, novas faixas 
construídas, que se alargavam progressivamente para áreas mais periféricas, basicamente industriais, reduzindo a homogeneidade social e arquitetónica da cidade antiga. Por seu turno, a cidade contemporânea passou a ser marcada pela existência de centralidade entre vários espaços. Isto faz com que os elementos geradores da cidade, em grande parte, a desapareçam, "porque o lugar mais acessível de uma aglomeração já não é, em regra, o centro geométrico, mas sim a via periférica, ou o seu encontro com anelares." As atividades e funções urbanas que eram exclusivas do centro passam para a franja da cidade. São característicos vários centros como, por exemplo, o de negócios, universitários, comerciais, desportivos, hospitalares, etc., que se instalam "no exterior do perímetro do antigo centro da cidade e impõem-se como centros secundários e concorrentes, originando a policentralidade" (Pumain, 2006, citado por Barreto, 2010: $32)$.

A intensificação do processo global de urbanização, conforme Cohen (2004), reúne vários aspectos da atual transição urbana, a saber: i) existência de uma escala de mudanças sem precedentes; ii) rapidez de ocorrência da urbanização; iii) mais rápida ocorrência de urbanização em países com baixa renda per capita e, no caso de África, existência de uma urbanização dissociada do desenvolvimento económico; iv) natureza e direção da mudança urbana mais dependente da economia global do que antes; v) contínua convergência dos estilos de vida urbano e rural, criando redundância na distinção tradicional entre esses dois grupos; e, vi) ocorrência de urbanização sobre um conjunto amplamente diferente de regimes demográficos.

De um modo geral, olhando concretamente para o carácter contemporâneo das cidades dos PALOP, encontramos similaridades nas últimas décadas no que diz respeito a intensificação do processo global de urbanização que, não tendo sido homogéneo, foi problemático, sobretudo ao coincidir com profundas alterações políticas e limitações económicas que constrangeram a capacidade pública de planeamento e de atuação. Este facto resultou na produção de espaços de intensa precariedade e de manifestação de variadas formas de pobreza. Em Maputo, como em outras cidades dos PALOP, os novos habitantes urbanos, entre eles os fugidos dos conflitos político-militares, concentraramse nas zonas periurbanas cujos assentamentos, nascidos em zonas precárias, continuam a apresentar graves lacunas de infraestruturação, e têm sido marcadas por carências habitacionais (Fernandes \& Nascimento, 2018).

Deste modo, a expansão urbana no quadro da atual transição urbana e da nova economia global, constitui um enorme desafio sobretudo para os países africanos de renda per capita baixa, cuja ocorrência da urbanização tem sido rápida e dissociada do desenvolvimento económico. Acresce-se a esse desafio, particularmente em Moçambique, uma população urbana de mais de $70 \%$ que, segundo Silva, Lima e Ramos (2018), vive em assentamentos informais, com características de "bairros de lata", sobretudo na cidade de Maputo, com crescimento denso e desregulado. A rápida expansão urbana, "muitas vezes, desordenada envolvendo construções, algumas ilegais, incluindo a falta de ordenamento territorial origina, entre outros problemas, os relacionados com a saúde e o bem-estar da população da cidade" (Ombe, 2018: 99). Nesse processo ocorre, entre outros, o descompasso entre a distribuição espacial da população e a localização dos equipamentos públicos, a invasão de áreas fisicamente inadequadas ao edificado (tais como depressões hidromórficas, ecossistemas costeiros de terras húmidas, dunas costeiras íngremes, etc.), rápido crescimento populacional com prevalência de doenças infectocontagiosas (Ombe, 2018).

Os espaços urbanos em Moçambique bem como de toda a África subsaariana resultaram de um processo alógeno, em função de interesses exteriores (coloniais), "copiando" modelos e perceções de organização do espaço oriundos das realidades das 
metrópoles coloniais, e "colando-os" num território para o qual se mantiveram, durante muito tempo, como corpos estranhos e antagónicos (Araújo, 2003). Estavam assim criadas condições para a diferenciação socio-espacial caracterizada pela existência de um centro urbano planificado, com a possibilidade de expansão pela periferia urbana em seu redor que, no geral, se transformou em repositório espacial de precariedade e pobreza, espaço de maior intensificação da urbanização tendente a uma policentralidade.

\section{Contextualização e tipologias de expansão urbana}

No processo de expansão urbana o crescimento da população urbana joga um papel importante. Pode resultar, segundo Cohen (2004), da migração rural-urbana, do crescimento natural ou mesmo da anexação e reclassificação de terras em redor da periferia, tornando-as urbanas. Esse processo, por exemplo, no caso de vários países da África subsaariana, incluindo Moçambique, é acompanhado de segregação socio-espacial urbana. Naciff, Kneib e Amaral (2019), baseados em Santos (2008), apontam a segregação urbana no quadro de exclusão do sistema das cidades uma vez que o termo induz à perceção de separação espacial de grupos sociais nas cidades e até é tratada, incluindo na política pública, como uma polarização secundária relativamente ao polo central (grande cidade).

A distribuição de grupos sociais no espaço urbano, conformada com uma determinada morfologia urbana, tem vindo a criar interesse entre pesquisadores, levandoos a criar modelos explicativos. Por exemplo, já em meados da década de 1910 a designada Escola de Chicago de Sociologia Urbana procurava explicações sobre a complexidade do fenómeno urbano, buscando padrões de regularidade, o que levou à conceção de teorias explicativas das formas urbanas. Estas tinham o centro da cidade como referência. Destacaram-se, assim, o modelo urbano das zonas concêntricas, de Ernest Burgess, o modelo dos sectores, de Homer Hoyt, e o modelo multinucleado, de Chauncy Harris e Edward Ullman. O modelo de Burgess, elaborado em 1925, preconizava que os usos do solo e as áreas residenciais se dispunham em forma de anéis concêntricos em torno de um centro (o CBD - Central Business District). Estes usos resultavam das relações de competição interpessoal, do domínio, da invasão-sucessão e da segregação. Era, pois, uma estruturação urbana em função da desigual capacidade económica das diferentes atividades e dos grupos sociais face ao valor do solo, tendente a diminuir do centro para a periferia. Em oposição à distribuição concêntrica das indústrias e das áreas residenciais, Hoyt defendia uma disposição em forma de cunhas ou sectores ao longo das vias principais cuja acessibilidade, originaria variações nos valores do solo e uma organização sectorial dos usos do solo (Martin, 1991 citado por Barreto, 2010). O modelo multinucleado ou dos "múltiplos núcleos", de Harris e Ullman, diferentemente dos dois anteriores, defendia que o padrão de uso da terra de muitas cidades não era estabelecido em torno de um centro único, mas sim de diversos núcleos separados (Harris e Ullman, 2005 citados por Pereira, 2017).

Os padrões de uso do solo urbano apresentados por estes modelos apresentam um carácter descritivo, ainda que sejam de algum modo complementares. Outras críticas feitas aos modelos prendem-se com o facto de terem negligenciado o papel da economia global, as remunerações da força de trabalho (seguindo as localizações das indústrias e dos serviços), o papel do Estado, os agentes que representam posições de classe diferentes (Gottdiener e Feagin, 1989 citados por Pereira, 2017), e o carácter da expansão de muitas cidades produzidas pela colonização europeia, sobretudo no caso dos PALOPs.

O processo de expansão urbana pode ocorrer seguindo duas etapas distintas, a saber: i) a do "crescimento compacto, em forma de anéis concêntricos, invadindo os 
espaços mais próximos, integrando-os à economia urbana" e, ii) a de urbanização de áreas mais distantes (dezenas de quilómetros), etapa denominada como difusa ou dispersa (España, 1991, referido por Vale e Gerardi, 2006: 231). O efeito da expansão e dispersão da cidade dá lugar a espaços sociais específicos, só parcialmente assimilados pelo complexo crescimento urbano, que conservam muitas das características típicas do âmbito rural, "mas sem que isso signifique que econômica ou socialmente dependam dele. Trata-se de uma forma de ocupação do território que não é nem propriamente rural, nem tampouco urbana" (Entrena, 2003: 65).

O conceito de expansão urbana, como processo, é atinente às dinâmicas da cidade que resultam ou justificam o seu crescimento. $\mathrm{O}$ referido processo, tomando em conta $\mathrm{o}$ resultado da ocupação do solo, pode ser do tipo crescimento territorial intensivo ou extensivo. A menor ou maior intensidade pela qual a cidade vai passando, desde a sua génese, vai então resultar na sua expansão, o que implica crescimento nos seus aspectos demográficos, físico (território da cidade). Expansão urbana é, assim, sinónimo de crescimento urbano. A cidade cresce ampliando territorialmente a sua área urbana (perímetro urbano), aumentando a sua mancha urbana ou parcelando o solo em áreas não ocupadas (Japiassú \& Lins, 2014).

A expansão urbana é, assim, um processo de ocupação do solo por meio da densificação e/ou ampliação sucessiva da sua área urbana ao longo do tempo. Vários tipos e formas podem ocorrer. A densificação pode ter uma dimensão edificatória (p. ex.: intensa verticalização), dimensão demográfica (p. ex.: aumento populacional) e mista (interação destas duas). A ampliação da área urbana, por seu turno, pode resultar de um plano de ordenamento territorial ou ocorrer à margem deste (p. ex.: urbanização informal).

Sobre as formas de crescimento territorial urbano intensivo e extensivo Japiassú \& Lins (2014) notam que o primeiro pode ser central ou periférico. O crescimento intensivo central caracteriza-se por uma alta densidade ocupacional nos centros urbanos, ocorrendo por meio da verticalização e pela fragmentação ou extensão das unidades residenciais em assentamentos populares. Por seu turno, o crescimento intensivo periférico ocorre às margens do centro urbano, mas pelos mesmos meios que o crescimento territorial intensivo central. Quanto à segunda forma (crescimento territorial urbano extensivo) cinco modelos são referidos, a saber: (i) por dispersão urbana, (ii) por difusão urbana, (iii) pela soma de novas áreas à mancha urbana, (iv) tentacular, e, (v) por anéis concêntricos (Idem).

A cidade difusa pode ser definida, como um fenómeno caracterizado pela “dispersão da população urbana pelo território, inclusive sobre as áreas rurais, sem que exista vínculo algum dessas pessoas com as atividades agrícolas" (Entrena Durán, 2003 apud Vale e Gerardi, 2006: 232). Segundo Naciff, Kneib e Amaral (2019), citando Litman (2015), uma cidade de tecido urbano disperso pode implicar a redução de acessibilidade, custos mais elevados para o fornecimento de infraestrutura e serviços públicos, viagens de longas distâncias, crescentes problemas de congestionamento e poluição, bem como a redução de oportunidades sociais e económicas.

As áreas periurbanas de urbanização difusa, de acordo com Entrena (2003), são geralmente ocupadas por uma população muito heterogênea quanto às suas motivações, que vai ao encontro, por exemplo, de um ambiente menos agitado ou mesmo a um reencontro com a natureza ou, simplesmente, busca ter acesso a uma moradia mais barata. As áreas periurbanas são caracterizadas por formas de urbanização dispersa em que, geralmente, torna-se difícil uma clara distinção entre o campo e a cidade. "Isto acontece em um contexto em que as periferias citadinas ou áreas periurbanas tendem a aumentar 
sua extensão e, sobretudo, ter limites cada vez mais indefinidos com respeito à área rural" (Entrena, 2003: 57).

O crescimento extensivo pela soma de novas áreas à mancha urbana ocorre por adição de áreas ao tecido urbano, caracterizando-se principalmente pela transição de terras de uso rural para urbano, por meio de parcelamento do solo, alteração no perímetro urbano ou criação/surgimento de novos bairros No modelo de crescimento extensivo tentacular a ocupação das terras é feita em função do sistema viário, as principais vias de acesso da cidade constituem vetores do crescimento territorial urbano (Japiassú \& Lins, 2014). No tipo "anéis concêntricos", um dos modelos do crescimento territorial extensivo, está presente o carácter radial tomando em conta um centro (Portella, et al, 2013 apud Japiassú \& Lins, 2014; Araújo, 1999).

\section{Dinâmicas do crescimento territorial extensivo da cidade de Maputo}

De génese colonial, fundada pelos portugueses em 1781 e elevada à cidade em 1887, a cidade de Maputo cresceu com base em infraestruturas portuárias e ferroviárias, prestando serviços aos países vizinhos do hinterland no âmbito da expansão da economia mineira. Beneficiou-se desde logo "de um plano que ditou a expansão da cidade baixa, em quadrícula, crescendo em mancha de óleo de forma contínua e compacta, galgando pelo planalto e afastando os subúrbios para uma periferia progressivamente mais longínqua (Raposo, Jorge, Viegas e Melo, 2012: 190).

Administrativamente, o estatuto de cidade cabia apenas à capital, Lourenço Marques (rebatizada Maputo após a independência), e, em redor da "cidade de cimento", distribuíam-se os subúrbios (a chamada "cidade de caniço"), que não sendo parte integrante da cidade segundo consideração das autoridades coloniais, serviriam para a expansão planificada da primeira (ver Viana, Rivas \& Natálio, 2013). O estabelecimento de um sector industrial limitado, nos anos 40, que processava matérias-primas destinadas ao consumo local, originou um rápido crescimento da ocupação nestas áreas, entre as novas zonas industriais. Eram áreas tidas como temporárias e os habitantes estavam desprovidos de quaisquer direitos de construção, tendo o governo adoptado uma política de "laissez faire" relativamente à ocupação (Jenkins, 2000 citado por Henriques \& Ribeiro, 2005).

Ainda que em termos administrativos a cidade se circunscrevesse à "cidade de cimento" já se desenhava a "invasão" desta para os espaços mais próximos que correspondiam à chamada "cidade de caniço". Entretanto, este segundo anel desenvolveuse integrado à economia urbana da primeira, tendo como aspeto diferenciador não só o contraste infraestrutural mas também cultural, económico e até político, constituindo, no quadro do desenvolvimento histórico e político, uma espécie de travão à referida "invasão".

Entre o primeiro anel e os restantes (Mapa 1), a segregação sócio espacial caracterizava-se por ser acentuada devido ao crescimento dos chamados bairros de "caniço", ou seja, de um lado estava a comunidade cosmopolita da cidade e, do outro, era notória a fragilidade morfológico-[infra]estrutural da população local. No final do período colonial o crescimento populacional torna-se saliente em bairros como Chamanculo, Jardim, Chinhambanine, Benfica, Mahotas e nos bairros litorais de Xaiase, Lichase e Laulane. Mesmo em bairros como S. José, Aeroporto, Tihabane e Kock, já com certo desenvolvimento anterior, a densificação concretizou-se na década Setenta, graças ao desenvolvimento do comércio e da indústria, bem como das vias de comunicação (Mendes, 1979: 90 apud Viana, Rivas \& Natálio, 2013). 
Deste modo, o processo de expansão da cidade de Maputo produziu uma forma urbana tradutora de contextos morfológicos contrastantes, de coexistência de processos formais e informais, dominada pela urbanização extensiva. A reconfiguração da cidadecapital moçambicana, principalmente a partir da retícula colonial de origem portuguesa, resultou de reformas determinantes ocorridas em poucas décadas (Viana, 2013), sem alterar a essência dos referidos contextos condicionados por uma economia praticamente dependente do exterior.

Mapa 1 - Tipologia das áreas urbanas da cidade de Maputo

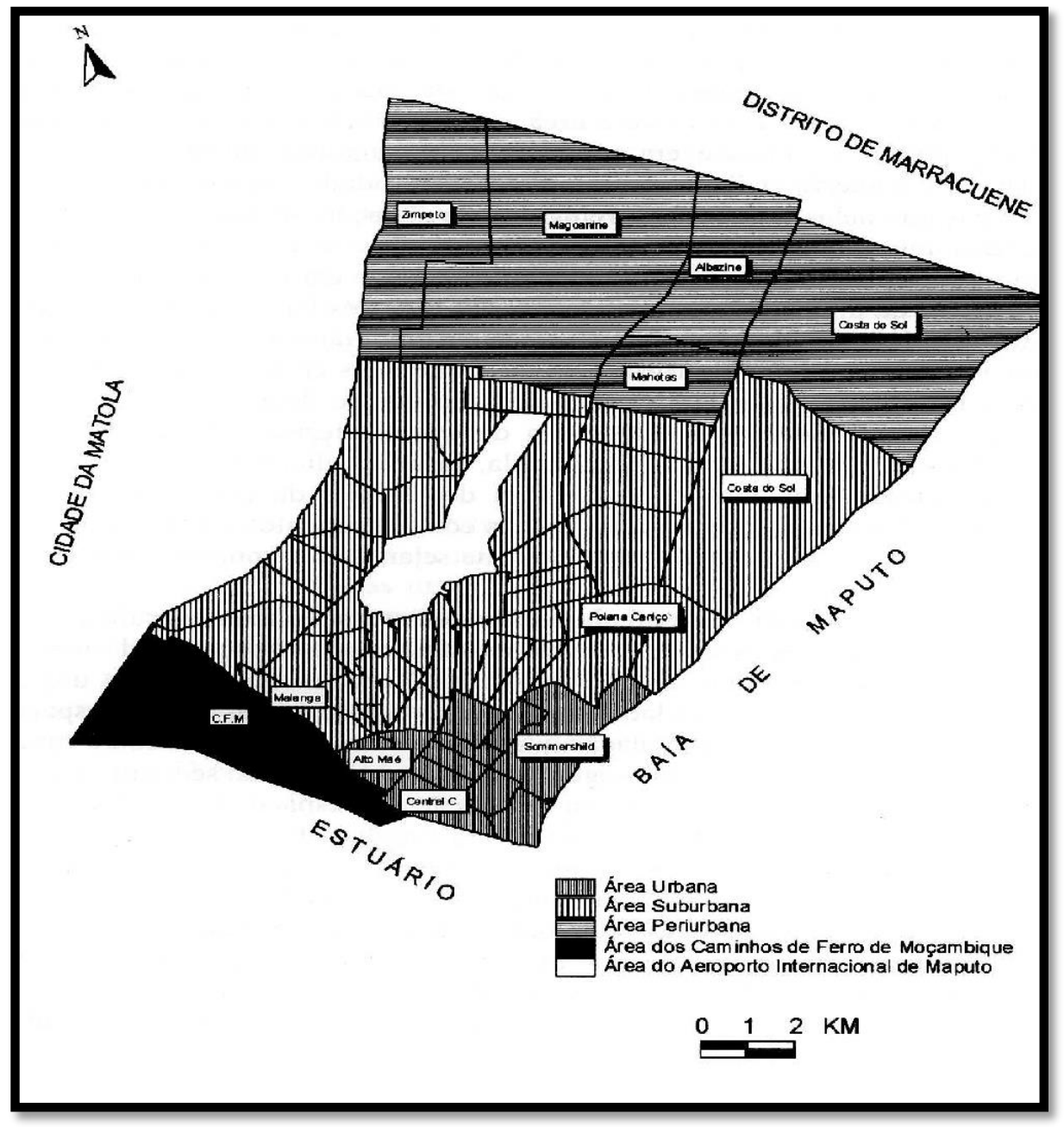

Fonte: Araújo (1999)

O traçado ortogonal bem definido, cercado por grandes avenidas e estradas asfaltadas, permanece marcante na área habitacional construída (núcleo urbano de Maputo) que se distribui entre quarteirões, representando apenas $9,1 \%$ da área total do município. Antes da independência de Moçambique a mesma era essencialmente habitada por portugueses. Após a independência, muitos habitantes dos subúrbios e da área periférica ocuparam os apartamentos e moradias abandonadas pelos ex-residentes (quando deixaram o país), tendo vários dos edifícios entrado em processo de degradação (Ver Henriques \& Ribeiro, 2005).

A segunda metade da década 70 constituiu um marco importante no processo de expansão urbana. Procurou-se ideologizar o espaço urbano a partir do avanço da população sobre a "cidade de cimento" baseado nas possibilidades existentes de 
materialização de uma linha marxista-leninista, alicerçada nas Nacionalizações ocorridas em 1975 e 1976. Segundo Viana (2013), foi nas designadas cinturas "suburbanas" e "periurbanas" que a urbanização extensiva [in]formal da cidade de Maputo encontrou "espaço para a sua expressão, entre a "ordem" e a aparente desordem - coabitação de contrários; isto é, reunindo a macroescala e estruturas de auto-organização espacial" (Viana, 2013: 5).

No entanto, essa mesma ideologização carecia de um trampolim político que pudesse catapultar a economia de Moçambique no sentido de evitar rutura com o passado recente. Assistiu-se, assim, por um lado, a uma descontinuidade no já fraco crescimento económico, alimentada pelos impactos negativos da instabilidade político-militar em paralelo com os dos efeitos perversos de eventos naturais como os ciclones, as cheias e secas cíclicas e, por outro, houve uma crescente ocupação do espaço urbano da periferia em um processo contínuo de espacialização da pobreza. A expansão urbana extensiva e predominantemente informal em Moçambique teve como uma das suas razões a economia centralizada, onde a terra era (e continua) considerada propriedade do Estado, retirando por isso espaço ao mercado formal de terras na cidade. Como refere Cohen (2007), citando Becker \& Morrison (1999), a falta de mercado de terras nas cidades, por exemplo, em cidades soviéticas, levou ao crescimento das mesmas em anéis concêntricos com vastas quantidades de terras não utilizadas em toda a cidade.

No caso da cidade de Maputo, o uso da terra para fins residenciais, abrangendo mais de $40 \%$ de toda a área terrestre da cidade, é considerado por Jenkins (2001) como o mais importante, tendo-se desenvolvido, basicamente, à margem de um mercado formal de terras na cidade. Este aspeto poderá permanecer, acompanhando a tendência de, por um lado, o uso económico da terra ser cada vez mais denso e, por outro lado, haver um desfasamento entre o crescimento do equipamento social e o uso da terra residencial. A predominância da informalidade na oferta real da terra residencial duplicou no período entre os Planos de Estrutura de 1985 e 1988, tendo-se expandido muito mais rapidamente em áreas residenciais não planeadas ou "informais" comparativamente às áreas planeadas ou "formais", ou seja, em 1985 a maior densidade habitacional era de 330 habitantes/hectare, acentuando-se em 1997 para 690 habitantes/hectare (Ver Jenkins, 2001).

O planeamento físico da cidade de Maputo, em 1985, consubstanciado no "Plano de Estrutura Cidade de Maputo", apontava para a necessidade de ocupação disciplinada do espaço urbano. Porém, em oposição, criaram-se desajustes morfológicos entre os modos de vida e de habitar e as dinâmicas próprias da cidade regulada. Um dinamismo que fez com que a atração da população pela cidade resultasse na expansão das áreas residenciais nos subúrbios. Neste sentido, por forma a aliviar as condições de sobreexploração de recursos nesses espaços, no quadro da rápida ocorrência da urbanização informal, caracterizada por habitabilidade básica precária, foi administrativamente estendido o limite urbano da capital até aos subúrbios, "passando a integrá-los, sendo adotadas medidas para melhorar as suas condições de vida urbana e ambientais" (Viana, Rivas \& Natálio, 2013: 14). Foram, assim, formalizados os "limites informais" da cidade. Araújo (1999) refere-se aos "anéis concêntricos" como estando presentes no crescimento da capital de Moçambique, identificando o $1^{\circ}$ anel como centro ou "urbano", o $2^{\circ}$ como "suburbano" e o $3^{\circ}$ anel como "periurbano" (Mapa 1). Ainda segundo o autor, o crescimento da "cidade de cimento" - $1^{\circ}$ anel, o urbano - ocorre "à custa de espaço que é alienado ao "caniço" - $2^{\circ}$ anel, o suburbano. Os bairros periurbanos ( $3^{\circ}$ anel) são aqueles considerados e tratados como uma reserva espacial "para a expansão da cidade que extravasa do centro (área urbana)" (Araújo, 1999: 176). 
Recuando no tempo, até 1975 , ano de independência política do País, a cidade colonial, a então Lourenço Marques, apresentava, por um lado, um relativo intenso crescimento vertical cujo aprimoramento arquitetónico estava virado para a "cidade de cimento" - o centro, correspondente ao primeiro anel; e, por outro lado, em redor do mesmo, na periferia, esses elementos distribuíam-se de forma cada vez mais dispersa e escassa constituindo-se em um segundo anel designado comummente por "cidade de caniço", espaço suburbano, cuja tipologia habitacional caracterizava-se num primeiro momento pelo predomínio do caniço. Num segundo momento, a partir da década de 90, este material de construção foi praticamente substituído pelo bloco e cimento. Depois deste segundo anel, o povoamento caracterizou-se, de um modo geral, pela dispersão, perfazendo um terceiro anel correspondente ao espaço periurbano.

É de notar que com a assinatura do Acordo Geral de Paz (AGP), em 1992, mais de 1,5 milhão de refugiados moçambicanos regressam ao País e deparam-se com serviços de saúde e saneamento em estado caótico. Grande parte dos mesmos ocupa as periferias das cidades moçambicanas, incluindo Maputo, que passa a receber também populações das zonas rurais e das cidades vizinhas (Ramos, Lima e Mendes, 2018). Ocorreram, a partir de então, mudanças políticas que levaram à privatização do conjunto habitacional e abriram espaço à reabilitação de alguns edifícios em algumas partes da "cidade de cimento", obrigando aos habitantes de menores posses financeiras a abandoná-los indo viver nos subúrbios e nas áreas periurbanas. Contavam-se em 1997, apenas 148.178 indivíduos a viver no núcleo urbano, ou seja, apenas $15,7 \%$ da população da cidade de Maputo (Henriques \& Ribeiro, 2005).

Em pouco menos de quadro décadas após a independência de Moçambique, a arquitetura de base colonial praticamente não foi abalada na sua perenidade, tendo o espaço urbano ganho nos últimos tempos elementos arquitetónicos Orientais (chineses), sobretudo, no seu centro. O processo de urbanização intensificou-se fazendo com que a cidade se densificasse no centro mas também nas cinturas "suburbanas" e "periurbanas", extravasando não propriamente do centro, mas ampliando-se a partir do espaço suburbano, ou seja, do segundo ao terceiro anel.

Nos últimos anos, a cidade de Maputo tem vindo a crescer muito rapidamente, transformando-se velozmente em uma grande metrópole, onde a diversificação das fontes de emprego e a garantia de provisão de serviços sociais influencia, em grande medida, na geração de "efeitos perversos do crescimento físico e da complexidade social (violência, desemprego e insegurança)" (Ombe, 2018: 104).

Em alguns bairros suburbanos de Maputo virados para a baía ou junto a vias principais observa-se a renovação, conduzida por particulares, associados a projecto residenciais de luxo (Costa do Sol e Polana Caniço), ou a atividades económicas (Maxaquene). Noutros casos, a mesma foi alvo de um plano parcial de urbanização sobre o tecido existente, como é o caso do bairro Maxaquene ou mesmo a área da Praça de Touros. A construção, na periferia, de grandes infraestruturas de saneamento ou viárias, de grandes equipamentos coletivos ou comerciais e de conjuntos empresariais e residenciais para classes mais favorecidas tem sido o produto de uma expansão urbana mercantilizada. Resultado desta produção do espaço é, por exemplo, a nova centralidade do Zimpeto, com os complexos habitacionais da Vila Olímpica (Raposo et al., 2012).

Os bairros da cidade que se expandiram recentemente constituem a franja urbana da cidade de Maputo. Vivem nesses bairros pessoas recém-chegadas e/ou indivíduos que foram "empurrados" devido à expansão da "cidade do cimento", em direção ao antigo subúrbio (Henriques \& Ribeiro, 2005), basicamente fora da lógica de um mercado formal de terras. Pontilham, nesses espaços, casas de elevado padrão, ou seja, de material 
durável, que se destacam num vasto espaço geográfico constituído por machambas espalhadas entre casas (bloco, cimento e zinco).

As várias habitações de elevado padrão que podem ser encontradas nos espaços suburbano e periurbano resultam do impacto da mercantilização do espaço geográfico, criando uma espécie de "efeito dominó" de poucos intervenientes diretos e de média ou longa duração. Ou seja, uma das formas desse efeito ocorre quando os lotes habitacionais mais ou menos apetecíveis das áreas suburbanas são negociados por imobiliárias ou indivíduos privados (mecanismos informais), por exemplo, em bairros como Polana Caniço (A ou B), Ka Maxakeni, Ka Lhamanculo, entre outros. Uma vez cedido o lote a família reinstala-se onde o valor da terra é relativamente mais baixo, geralmente em áreas periurbanas, coincidindo com espaços de maiores dimensões e habitação relativamente melhorada se comparada ao local de partida. A ocupação do novo local por esta família "empurrada" do subúrbio despoleta um processo onde a mesma também "empurra" uma outra de menores posses. Este "efeito dominó" pode ser desencadeado a partir do centro urbano para o subúrbio ou ainda para as áreas periurbanas o que não inibe uma situação contrária. Contribui neste processo de expansão a ação do Estado que obrigou ao reassentamento da população. São exemplos recentes a construção da ponte MaputoKatembe e o reassentamento da respetiva população afetada em Tenga; a construção da estrada Circular de Maputo e a indeminização de diversas famílias obrigadas a construir suas habitações em novas localizações.

\section{Considerações finais}

A tipologia da cidade de Maputo, marcadamente em forma de anéis concêntricos pontuando a urbanização difusa ou dispersa, enquadra-se nas duas etapas distintas da expansão urbana teorizadas por España (1991, referido por Vale e Gerardi, 2006). Na abordagem de Japiassú \& Lins (2014), a cidade de Maputo enquadra-se em grande medida na forma extensiva seguindo o modelo de crescimento territorial por anéis concêntricos e por dispersão ou difusão urbanas. Considerando a perspetiva histórica, a cidade de Maputo irradiou-se a partir de um centro urbano dinamizador dos espaços suburbanos e os periurbanos. Esse dinamismo foi, no entanto, refreado pela instabilidade político-militar, cujo impacto criou pressão em direção ao centro, numa transição urbana caracterizada pela rápida ocorrência de urbanização e dissociada do desenvolvimento económico. Contudo, a partir da primeira metade da década 90, a transição urbana é reforçada por um processo de mudança urbana mais dependente da economia global e pela convergência dos estilos de vida urbano e rural.

A tipologia de expansão da cidade de Maputo, em anéis concêntricos, constitui uma possibilidade de leitura do crescimento territorial urbano extensivo, sobretudo devido aos mecanismos informais de acesso à terra. A integração de Moçambique na economia regional, durante o período colonial, influenciou a expansão do espaço urbano diferenciando-o tanto em termos espaciais como sociais; uma diferenciação socioespacial que após a independência de Moçambique prevaleceu associada a uma economia altamente dependente da ajuda externa, distribuindo espacialmente a pobreza sobre o conjunto da morfologia urbana. Nos últimos tempos, a referida expansão urbana extensiva, genericamente do tipo anéis concêntricos, evidencia uma etapa crescentemente mais conformada com a urbanização dispersa e um sentido centro-periferia dominado por um mercado de terras informal com alguma visibilidade do mercado imobiliário formal. As transformações espaciais na cidade de Maputo, ainda que não desestruturem o carácter monocêntrico, já apresentam alguma tendência à policentralidade o que é sustentado pela 
atividade económica e social que vai ganhando substância em várias localizações da capital.

\section{Referências bibliográficas}

ARAÚJO, Manuel G. M. Cidade de Maputo; espaços contrastantes: do urbano ao rural. Finisterra - Revista Portuguesa de Geografia, Lisboa, XXXIV (67-68), p. 175-190, 1999.

ARAÚJO, Manuel G. M. Os Espaços Urbanos em Moçambique. GEOUSP Espaço e Tempo, São Paulo, n 14, p. 165-182, 2003.

BARRETO, Rogério. O centro e a centralidade urbana - aproximações teóricas a um espaço em mutação. Cadernos de Doutoramento em Geografia, v. 2, Porto: FLUP (Faculdade de Letras da Universidade do Porto), p. 23-41, 2010.

COHEN, Barney. Urban Growth in Developing Countries: A Review of Current Trends and a Caution Regarding Existing Forecasts. World Development. Elsevier. Vol. 32, No. 1, pp. 23-51, 2004.

ENTRENA, Francisco. Cidades sem limites. Trabalho, economia e tecnologia: novas perspectivas para a sociedade global. São Paulo: Tendenz; Bauru: Práxis, p. 54-87, 2003.

FERNANDES, Ana S. e NASCIMENTO, Augusto. O "Direito à Cidade" nos PALOP: Quatro décadas de expansão urbana, de políticas e de mutações sociais. Notas para uma investigação. Cadernos de Estudos Africanos [online]. no 35 [citado 2019-09-06], pp.109-132. $2018 . \quad$ Disponível em: <http://www.scielo.mec.pt/scielo.php?script=sci_arttext\&pid=S1645-

$37942018000100006 \& \operatorname{lng}=\mathrm{pt} \& \mathrm{nrm}=\mathrm{iso}>$.

ISSN

$1645-$

3794. http://dx.doi.org/10.4000/cea.2679.

HENRIQUES, Cristina \& RIBEIRO, Jorge. Habitat Typology in the African City contribution for the characterization of the residential land use in Maputo using multidimensional analysis. Conference: XIVth European Colloquium on Theoretical and Quantitative Geography, Tomar, Portugal, p. 1-17, 2005

JAPIASSÚ, Luana A. T. \& LINS, Regina D. B. As Diferentes Formas de Expansão Urbana. Revista Nacional de Gerenciamento de Cidades, v. 02, n. 13, pp. 15-25, 2014. JENKINS, Paul. Mercados de terras urbanas no Moçambique pós-socialismo Seu impacto sobre a população vulnerável: alternativas para melhorar o acesso à terra e o processo de desenvolvimento urbano. Edimburgo/Maputo: Centre for Environment \& Human Settlements, Edinburg College/ Centro de Estudos e Desenvolvimento do Habitat, da Faculdade de Arquitetura e Planeamento Físico da Universidade Eduardo Mondlane, 2001.

NACIFF, Yordana D. N., KNEIB, Erika C. e AMARAL, Camilo V. L. O pensamento sistêmico em análises urbanas: uma perspectiva para o problema da segregação socioespacial nas cidades. usjt • arq.urb • número $24 \mid$ pp. 8-25, janeiro - abril de 2019. 
OMBE, Zacarias A. Reflexão sobre a Saúde e o Bem-estar, em Maputo. In: SILVA, José J, LIMA, Samuel do Carmo e MENDES, Paulo C. Saúde Ambiental, Território e Promoção de Saúde em Maputo, Moçambique. Uberlândia (MG): Assis Editora, 2018, pp. 95-104.

PEREIRA, Cláudio S. S. O Centro da Cidade no Contexto da Estrutura(ção) Urbana: considerações cerca da "Teoria Urbana Convencional" e da "Teoria Crítica Urbana". Geo UERJ, Rio de Janeiro, n. 31, p. 669-697, 2017.

RAMOS, Joaquim D., LIMA, Samuel do Carmo \& MENDES, Paulo C. Políticas Públicas Percebidas em Chamanculo C. In: SILVA, José J., LIMA, Samuel do Carmo \& MENDES, Paulo C. Saúde Ambiental, Território e Promoção de Saúde em Maputo, Moçambique. Uberlândia (MG): Assis Editora, 2018, p. 191-201.

RAPOSO, Isabel S.; JORGE, Sílvia; VIEGAS, Sílvia e MELO, Vanessa. Luanda e Maputo: inflexões suburbanísticas da cidade socialista à cidade-metrópole neoliberal. urbe, Rev. Bras. Gest. Urbana [online]. 2012, vol.4, n. 2 [cited 2019-10-28], pp.189-205. Available from: <http://www.scielo.br/scielo.php?script=sci_arttext\&pid=S217533692012000200004\&lng=en\&nrm=iso>. ISSN2175-3369. http://dx.doi.org/10.7213/urbe.7395.

SILVA, José J., LIMA, Samuel do Carmo \& RAMOS, Joaquim D. Moçambique, um País de Contrastes. In: SILVA, José J., LIMA, Samuel do Carmo \& MENDES, Paulo C. Saúde Ambiental, Território e Promoção de Saúde em Maputo, Moçambique. Uberlândia (MG): Assis Editora, 2018, p. 21-36.

VALE, Ana R. \& GERARDI, Lúcia H. O. Crescimento Urbano e Teorias sobre o Espaço Periurbano: analisando o caso do município de Araraquara (SP). In: GERARDI, Lucia H. O. \& CARVALHO, Pompeu F. Geografia: ações e reflexões. Rio Claro: UNESP/IGCE e AGETEO, p. 231-246, 2006, 434 p.

VIANA, D. L. A urbanização extensiva (in)formal em Maputo a partir da retícula colonial. Atas do Congresso Saber Tropical em Moçambique: História, Memória e Ciência. Lisboa, Portugal: Instituto de Investigação Científica Tropical, 2013.

VIANA, D. L., Rivas, J. L. \& Natálio, A. Apreendendo com a morfologia urbana de Maputo (in)formal. Revista de Morfologia Urbana (1). Porto, Portugal: Rede Lusófona de Morfologia Urbana, p. 17-30, 2013. 